\title{
O Measles-Associated Acute Acalculous Cholecystitis ${ }^{* \#}$
}

\author{
Caroline Clerckx ${ }^{1}$, Jean-Cyr Yombi ${ }^{2}$, Leila Belkhir ${ }^{2}$, Bernard Vandercam ${ }^{2 \dagger}$ \\ ${ }^{1}$ Divisions of Internal Medicine, Cliniques Universitaires Saint-Luc, Université Catholique de Louvain, Brussels, Belgium; ${ }^{2}$ Divisions \\ of Tropical and Infectious Diseases, Cliniques Universitaires Saint-Luc, Université Catholique de Louvain, Brussels, Belgium. \\ Email: ${ }^{\dagger}$ vandercam@intr.ucl.ac.be
}

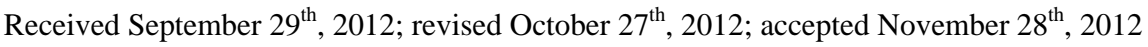

\begin{abstract}
Background: Measles is a highly contagious viral infection whose complications most commonly involve the respiratory tract and the central nervous system. We report here what we think to be the first case of acute acalculous cholecystitis occurring during the course of measles. Case Presentation: A 22-year-old female presented with fever, sore throat, coryza and an erythematous maculopapular eruption. The diagnosis of measles was confirmed by the presence of IgM antibodies to measles virus in the absence of IgG antibodies. After initial favorable evolution, she developed abdominal pain with positive Murphy's sign and elevated liver enzymes. Ultrasonographic examination of the abdomen showed thickening $(6.5 \mathrm{~mm})$ of the gallbladder wall in the absence of stones or biliary tract dilatation. Evolution was spontaneously favorable, so that neither antibiotic therapy nor surgical intervention were necessary. Conclusion: In the context of worldwide recent measles outbreak, we think that clinicians should be aware of the possible occurrence of acute acalculous cholecystitis, a pathology usually associated with a high rate of complications.
\end{abstract}

Keywords: Acalculous Cholecystitis; Measles

\section{Introduction}

Measles is a highly contagious viral infection that predominately affects children, although it may occur in any age group, especially in the context of recent outbreak. The illness is characterized by fever, conjunctivitis, coryza, cough, Koplik's spots, and a diffuse erythematous maculopapular rash [1-3]. Complications most commonly involve the respiratory tract and the central nervous system. Other complications include otitis media, sinusitis, stomatitis, diarrhea, subclinical hepatitis (occurring in at least $30 \%$ of adult patients), appendicitis, ileocolitis, pericarditis and myocarditis [1].

To our knowledge, Acute Acalculous Cholecystitis (AAC) has never been reported. We report here a case of AAC occurring during the early convalescence phase of measles.

\section{Case Presentation}

A 22-year-old female presented to the emergency department with a 6-day history of fever, sore throat and coryza. She also complained of an erythematous maculopapular eruption that started 3 days before on the face and the upper trunk, and then spread to the lower trunk

${ }^{*}$ Consent: Written informed consent was obtained from the patient for publication of this Case report.

"Disclosure: The authors declare that they have no conflict of interest.

${ }^{\dagger}$ Corresponding author. and extremities. The patient had never received the MMR (Measles, Mumps, Rubella) vaccine.

Physical examination revealed pharyngitis, stomatitis, conjunctivitis, posterior cervical and axillary lymphadenopathy. The maculopapulous eruption was diffuse, and confluent on the face and upper body. Abdominal examination was normal.

Laboratory studies showed white blood cell count of $4.1 \times 10^{9} / \mathrm{L}$, in the presence of lymphopenia and thrombocytopenia. The C-Reactive Protein (CRP) was $23 \mathrm{mg} / \mathrm{dl}$ (Normal Value $\mathrm{Nl}<1 \mathrm{mg} / \mathrm{dl}$ ). Liver function tests showed mildly elevated AST at $68 \mathrm{IU} / \mathrm{L}(\mathrm{Nl}<33 \mathrm{IU} / \mathrm{L}), \mathrm{LDH}$ at $374 \mathrm{IU} / \mathrm{L}(\mathrm{Nl}<192 \mathrm{IU} / \mathrm{L}), \mathrm{GGT}$ at $98 \mathrm{IU} / \mathrm{L}(\mathrm{Nl}<50 \mathrm{IU} / \mathrm{L})$, direct bilirubin level of $0.3 \mathrm{mg} / \mathrm{dl}(\mathrm{Nl}<0.2 \mathrm{mg} / \mathrm{dl})$, with a normal total bilirubin level of $1.1 \mathrm{mg} / \mathrm{dl}(\mathrm{Nl} 0.3-1.2$ $\mathrm{mg} / \mathrm{dl})$. Pancreatic enzyme levels were normal.

The diagnosis of measles was confirmed by the presence of IgM antibodies to measles virus in the absence of IgG antibodies. Serologic tests for cytomegalovirus, rubella, hepatitis $\mathrm{A}, \mathrm{B}, \mathrm{C}$, and HIV were negative, and showed immunization against Epstein-Barr Virus.

Over the next 24 hours, her symptoms improved and the rash progressively faded, but she developed abdominal pain. Abdominal examination revealed right upper quadrant tenderness with a positive Murphy’s sign. Laboratory tests showed a regression of CRP but an elevation of AST at $89 \mathrm{IU} / \mathrm{L}(\mathrm{Nl}<33 \mathrm{IU} / \mathrm{L}), \mathrm{ALT}$ at $87 \mathrm{IU} / \mathrm{L}$ 
$(\mathrm{Nl}<63 \mathrm{IU} / \mathrm{L})$, and GGT at $118 \mathrm{IU} / \mathrm{L}(\mathrm{Nl}<50 \mathrm{IU} / \mathrm{L})$, with normal total and direct bilirubin.

Ultrasonographic examination of the abdomen showed thickening $(6.5 \mathrm{~mm})$ of the gallbladder wall in the absence of stones or biliary tract dilatation.

No antibiotic therapy was initiated, and the patient spontaneously improved within three days with regression of abdominal pain and normalization of liver enzymes.

Follow-up two months later showed a normal gallbladder wall on ultrasound, and the presence of IgG antibodies to measles virus with disappearance of IgM antibodies on serologic tests.

\section{Discussion}

Our patient developed AAC in the recovery phase of measles. Although measles has been often associated with hepatitis [4-6], this is to our knowledge, the first case of measles-related AAC.

AAC is defined as an acute necroinflammatory disease of the gallbladder in the absence of cholelithiasis. It accounts for approximately $10 \%$ (range, $2 \%-15 \%$ ) of all cases of acute cholecystitis, and occurs mostly in critically ill or injured patients [7]. Given the high mortality of untreated disease, treatment usually consists of cholecystectomy or percutaneous cholecystostomy, with concomitant antibiotic therapy [7-9].

The pathogenesis of AAC is complex, involving ischemic and chemical injury. Gallbladder ischemia and reperfusion injury is central to the pathogenesis of AAC, as demonstrated by gallbladder microangiography [9]. Whereas gallstone-related cholecystitis is associated with arterial dilatation and extensive venous filling, AAC is characterized by multiple arterial occlusions and minimal-to-absent venous filling, suggesting that vascular occlusion and disruption of the microcirculation are central to the pathogenesis of AAC $[8,10]$. Bile stasis represents another main pathogenic factor, resulting in concentration of bile, which can inspissate in the absence of gallbladder emptying, producing a functional obstruction to outflow from the gallbladder. Moreover, bile stasis may also alter the chemical composition of bile, which may promote local gallbladder mucosal injury [8].

Infection usually represents a secondary phenomenon and involves Gram-negative enteric flora. However, infection can also represent the primary phenomenon, as it has been described with Staphylococcus aureus, Salmonella sp, Campylobacter jejuni, Mycoplasma pneumoniae, Clostridium perfringens, Brucella sp, Candida sp, Cryptosporidium sp, Microsporidium sp, Leptospira sp, Shistosoma sp, Rickettsia sp, Coxiella sp, Isospora sp, Cyclospora sp, Vibrio cholerae, Mycobacterium tuberculosis, Leishmania sp and Plasmodium falciparum and vivax $[7,9,11]$. Although AAC caused by viral infections is ex- tremely rare, it has been reported in the course of infections by Epstein-Barr virus, Cytomegalovirus, hepatitis A and B virus and Dengue virus [12-14].

The pathogenesis of AAC in the course of measles remains unclear. A direct viral action is suggested by the results of autopsy reports [15,16], in which viral antigen was found in a variety of epithelial cell types, including biliary duct epithelium. Moreover, we speculate that the particular tropism of measles virus for vascular endothelial cells $[3,17]$ could play a role in the genesis of microangiopathy observed in AAC [10]. The role of bile stasis induced by fever, dehydration and prolonged fasting may also be evocated.

\section{Conclusions}

We present here the first case of AAC associated with measles. In the present context of resurgence of measles, clinicians should be aware that AAC may occur during the course of measles. Ultrasound of the gallbladder should be considered in patients with measles and right upper quadrant tenderness.

Because of prompt resolution of symptoms of cholecystitis in the presented case, neither antibiotic therapy nor surgical intervention seemed mandatory. However, because of the high rate of complications observed in AAC in critically ill patients, antibiotic treatment and surgery might be considered in case of unfavorable evolution.

\section{REFERENCES}

[1] C. Sabella, "Measles: Not Just a Childhood Rash," Cleveland Clinic Journal of Medicine, Vol. 77, No. 3, 2010, pp. 207-213. doi:10.3949/ccjm.77a.09123

[2] F. C. Robbins, "Measles: Clinical Features,” American Journal of Diseases of Children, Vol. 103, 1962, pp. 266-273.

[3] A. A. Gershon, "Measles Virus (Rubeola),” In: G. L. Mandell, J. E. Bennett and R. Dolin, Eds., Mandell, Douglas and Bennett's Principles and Practice of Infectious Diseases, 7th Edition, Expert Consult Premium Edition, Netherlands, 2010, pp. 2229-2236.

[4] H. Shalev-Zimels, Z. Weizman, C. Lotan, D. Gavish, Z. Ackerman and A. Morag, "The Extent of Measles Hepatitis in Various Ages,” Hepatology, Vol. 8, No. 5, 1988, pp. 1138-1139. doi:10.1002/hep.1840080529

[5] R. Khatib, M. Siddique and M. Abbass, "Measles Associated Hepatobiliary Disease: An Overview,” Infection, Vol. 21, No. 2, 1993, pp. 112-114. doi:10.1007/BF01710744

[6] D. Gavish, Y. Kleinman, A. Morag and T. Chajek-Shaul, "Hepatitis and Jaundice Associated with Measles in Young Adults: An Analysis of 65 Cases," Archives of Internal Medicine, Vol. 143, No. 4, 1983, pp. 674-677. doi:10.1001/archinte.1983.00350040064008

[7] J. L. Huffman and S. Schenker, "Acute Acalculous Cholecystitis: A Review,” Clinical Gastroenterology and Hepa- 
tology, Vol. 8, No. 1, 2010, pp. 15-22. doi:10.1016/j.cgh.2009.08.034

[8] P. S. Barie and S. R. Eachempati, "Acute Acalculous Cholecystitis,” Current Gastroenterology Reports, Vol. 5, No. 4, 2003, pp. 302-309. doi:10.1007/s11894-003-0067-x

[9] K. Julka and C. W. Ko, "Infectious Diseases and the Gallbladder," Infectious Disease Clinics of North America, Vol. 24, No. 4, 2010, pp. 885-898.

[10] T. Hakala, P. J. Nuutinen, E. T. Ruokonen and E. Alhava, "Microangiopathy in Acute Acalculous Cholecystitis," British Journal of Surgery, Vol. 84, No. 9, 1997, pp. 12491252. doi:10.1002/bjs.1800840915

[11] J. C. Yombi, C. M. Meuris, A. M. van Gompel, M. Ben Younes and B. C. Vandercam, “Acalculous Cholecystitis in a Patient with Plasmodium Falciparum Infection: A Case Report and Literature Review,” Journal of Travel Medicine, Vol. 13, No. 3, 2006, pp. 178-180. doi:10.1111/j.1708-8305.2006.00023.x

[12] M. Gora-Gebka, A. Liberek, W. Bako, A. Szarszewski, B. Kaminska and M. Korzon, "Acute Acalculous Cholecystitis of Viral Etiology-A Rare Condition in Children," Journal of Pediatric Surgery, Vol. 43, No. 1, 2008, pp. 2527. doi:10.1016/j.jpedsurg.2007.10.073

[13] S. O. Arya, A. Saini, M. El-Baba, H. Salimnia and N. Abdel-
Haq, "Epstein Barr Virus-Associated Acute Acalculous Cholecystitis: A Rare Occurrence but Favorable Outcome," Clinical Pediatrics, Vol. 49, No. 8, 2010, pp. 799-804. doi:10.1177/0009922810363729

[14] S. Mourani, S. T. Dobbs, R. M. Genta, A. K. Tandon and B. Yoffe, "Hepatitis A Virus-Associated Cholecystitis," Annals of Internal Medicine, Vol. 120, No. 5, 1994, pp. 398400.

[15] H. R. Brown, N. L. Goller, R. D. Rudelli, J. Dymecki and H. M. Wisniewski, "Postmortem Detection of Measles Virus in Non-Neural Tissues in Subacute Sclerosing Panencephalitis,” Annals of Neurology, Vol. 26, No. 2, 1989, pp. 263-268. doi:10.1002/ana.410260213

[16] T. R. Moench, D. E. Griffin, C. R. Obriecht, A. J. Vaisberg and R. T. Johnson, “Acute Measles in Patients with and without Neurological Involvement: Distribution of Measles Virus Antigen and RNA,” Journal of Infectious Diseases, Vol. 158, No. 2, 1988, pp. 433-442. doi:10.1093/infdis/158.2.433

[17] D. E. Griffin, B. J. Ward and L. M. Esolen, "Pathogenesis of Measles Virus Infection: A Hypothesis for Altered Immune Responses,” Journal of Infectious Diseases, Vol. 170, No. S1, 1994, pp. S24-S31. doi:10.1093/infdis/170.Supplement_1.S24 